\title{
Trends in national suicide rates for Scotland and for England \& Wales, 1960-2008
}

Pearl L. H. Mok, Navneet Kapur, Kirsten Windfuhr, Alastair H. Leyland, Louis Appleby, Stephen Platt and Roger T. Webb

\section{Background}

Suicide rates in Scotland have increased markedly relative to those in England in recent decades.

\section{Aims}

To compare changing patterns of suicide risk in Scotland with those in England \& Wales, 1960-2008.

\section{Method}

For Scotland and for England \& Wales separately, we obtained national data on suicide counts and population estimates. Gender-specific, directly age-standardised rates were calculated.

\section{Results}

We identified three distinct temporal phases: 1960-1967, when suicide rates in England \& Wales were initially higher than in Scotland, but then converged; 1968-1991, when male suicide rates in Scotland rose slightly faster than in England \& Wales; and 1992-2008, when there was a marked divergence in national trends. Much of the recent divergence in rates is attributable to the rise in suicide among young men and deaths by hanging in Scotland. Introduction of the 'undetermined intent' category in 1968 had a significant impact on suicide statistics across Great Britain, but especially so in Scotland.

\section{Conclusions}

Differences in temporal patterns in suicide risk between the countries are complex. Reversal of the divergent trends may require a change in the perception of hanging as a 'painless' method of suicide.

\section{Declaration of interest}

None.
Although suicides accounted for only around 1\% of the total number of deaths in the UK in recent years, ${ }^{1}$ they are a key contributor to premature mortality when considered from the perspective of potential years of life lost. ${ }^{2}$ Until the late 1960s, suicide rates in Scotland were lower than in many other European countries, including England. ${ }^{3,4}$ Since then, the national rate in Scotland has risen markedly and is now the highest of all the UK countries. ${ }^{1,5}$ The purpose of this paper is to clarify in more detail the changing patterns of suicide risk between Scotland and England \& Wales over the past five decades, as a basis for understanding the reasons behind the trends. Most of the crossnational comparisons for Scotland and England \& Wales, such as those by Kreitman and Crombie, ${ }^{4,5}$ were published at least two decades ago and therefore do not explore recent trends, whereas more recent studies cover only short periods. ${ }^{1,6}$ We built upon some of this earlier research comparing the patterns of suicides between Scotland and England \& Wales, and greatly extended the time scale by examining the period 1960-2008. In particular, we investigated how gender-, age- and method-specific rates have varied between the countries, as previous studies have reported that suicide rates not only differed by gender and age but are also influenced by ease of access to different suicide methods and changing culture. ${ }^{7,8}$

\section{Method}

\section{Suicide data}

Suicide data for England \& Wales were extracted from the Office for National Statistics (ONS) The 20th Century Mortality Files (for 1960-1992), ${ }^{9}$ or obtained directly from ONS (1993-2008). Data for Scotland were taken from the Registrar General for Scotland Annual Reports (1961-1987, 1996-2000), ${ }^{10}$ the Vital Events Reference Tables published by the General Register Office for Scotland (GROS) for 2001-2008, ${ }^{11}$ or obtained directly from
GROS (1960, 1988-1995). Over the study period, mortality data published by the ONS and its predecessor, the Office of Population Censuses and Surveys, have been based either on year of occurrence or year of registration, ${ }^{12}$ whereas in Scotland the published figures have been based only on the latter. For consistency, all the suicide data reported here are based on year of registration and include deaths of non-residents.

Suicides are defined according to the ICD coding ranges shown in the Appendix. The category 'injury undetermined whether accidentally or purposely inflicted' was introduced in 1968. In the UK it has become customary for researchers to include these deaths as suicides, as there is evidence that the majority of such injuries are self-inflicted, although there is insufficient proof to determine whether the deceased intended to kill themselves. ${ }^{13-15}$ In our study, 'suicides' from 1968 onwards include deaths from self-inflicted injury or intentional self-harm, as well as those that are of undetermined intent. The codes E988.8 (ICD-9) and Y33.9 (ICD-10) were excluded, as these are used in England \& Wales where the coroner's verdict is pending, and most of such cases are subsequently found to be homicides. ${ }^{1}$ We did, however, include Y87.0 (ICD-10, sequelae of intentional self-harm) and Y87.2 (ICD-10, sequelae of event of undetermined intent). Although they are not counted in the official suicide statistics in England \& Wales, they have been included in the Scottish statistics. ${ }^{1}$ The ICD codes used to define specific suicide methods are shown in the Appendix.

\section{Statistical analysis}

Suicide rates were calculated from population estimates for age 15 years and over, from ONS and GROS, and have been directly age-standardised using the World Health Organization's (WHO) European Standard Population stratified by 5 -year age strata. This was performed for suicides at all ages (15 years and over) and within three broad age groups (15-44 years, 45-64 years, 65 years 
and over). Gender-specific rates per 100000 population per year are reported throughout. For analyses stratified by age group and suicide method, where there are larger annual fluctuations because of small numbers, suicide rates are reported as 3-year averages, centred on the middle year of each 3-year period. To formally assess within- and between-nation temporal trends, log-linear Poisson regression models were fitted, with a two-sided significance level of $P=0.05$. All analyses were conducted using intercooled Stata software version 11.1 on Windows.

\section{Results}

\section{Overall suicide rates}

Figure 1 compares the temporal trends between England \& Wales and Scotland, with 'undetermined intent' deaths included in the figures after the introduction of this category in 1968. There was a sudden and large increase in suicide rates in 1968, particularly in Scotland, which coincided with the crossover in national rates between Scotland and England \& Wales. Perhaps the most striking feature is that three clear temporal phases can be distinguished, as described below. Results from Poisson regression models are detailed in online Tables DS1-4.

\section{Phase 1}

During 1960-1967 male suicide rates fell overall across Great Britain, although the decline in Scotland was not statistically significant $(P=0.07)$. Similarly, female suicide rates for England \& Wales fell during these years, but the changes in Scotland were non-significant $(P=0.67)$. Towards the end of this first phase, gender-specific rates converged between the countries.

\section{Phase 2}

The first phase was followed by an increase in male suicide rates between 1968 and 1991, with the Scottish rates rising slightly faster than those in England \& Wales $(P=0.01$ for test of a difference between countries). Unlike the pattern for men, female suicide rates in England \& Wales and Scotland fell overall during the second phase.

\section{Phase 3}

A marked divergence in trends between the countries can be seen in the third and final phase, 1992-2008 $(P<0.001$ for men and $P=0.001$ for women, for between-country difference). During this period, although there was an overall decline in suicide rates for men in England \& Wales, male rates in Scotland rose between 1992 and 2002. After 2002, however, changes in the male Scottish rates were not statistically significant $(P=0.27)$. Having fallen during the second phase, female rates continued to fall during the third phase, with a faster rate of decline being observed in England \& Wales than in Scotland $(P=0.001)$.

We conducted some further analyses that we have not presented graphically. When only the suicide verdicts were examined (with the undetermined deaths excluded), the overall patterns were similar to those shown in Fig. 1, but the crossover in rates between the countries occurred 2 years later for both male and female suicide.

\section{Age-specific suicide rates}

Figure 2 shows changes in age-specific suicide rates for the age groups 15-44 years, 45-64 years and 65 years and over. There has been a marked increase in young adult male suicide across Great Britain since the late 1960s, particularly in Scotland. Further analyses by 10 -year age strata revealed that the rise in male suicide was particularly pronounced among those aged 15-34 years. Suicide among young Scottish women also rose overall during 1968-2008, but at a much slower rate than for Scottish men, whereas the young adult female suicide rate in England \& Wales saw an overall decline during these four decades. In contrast to

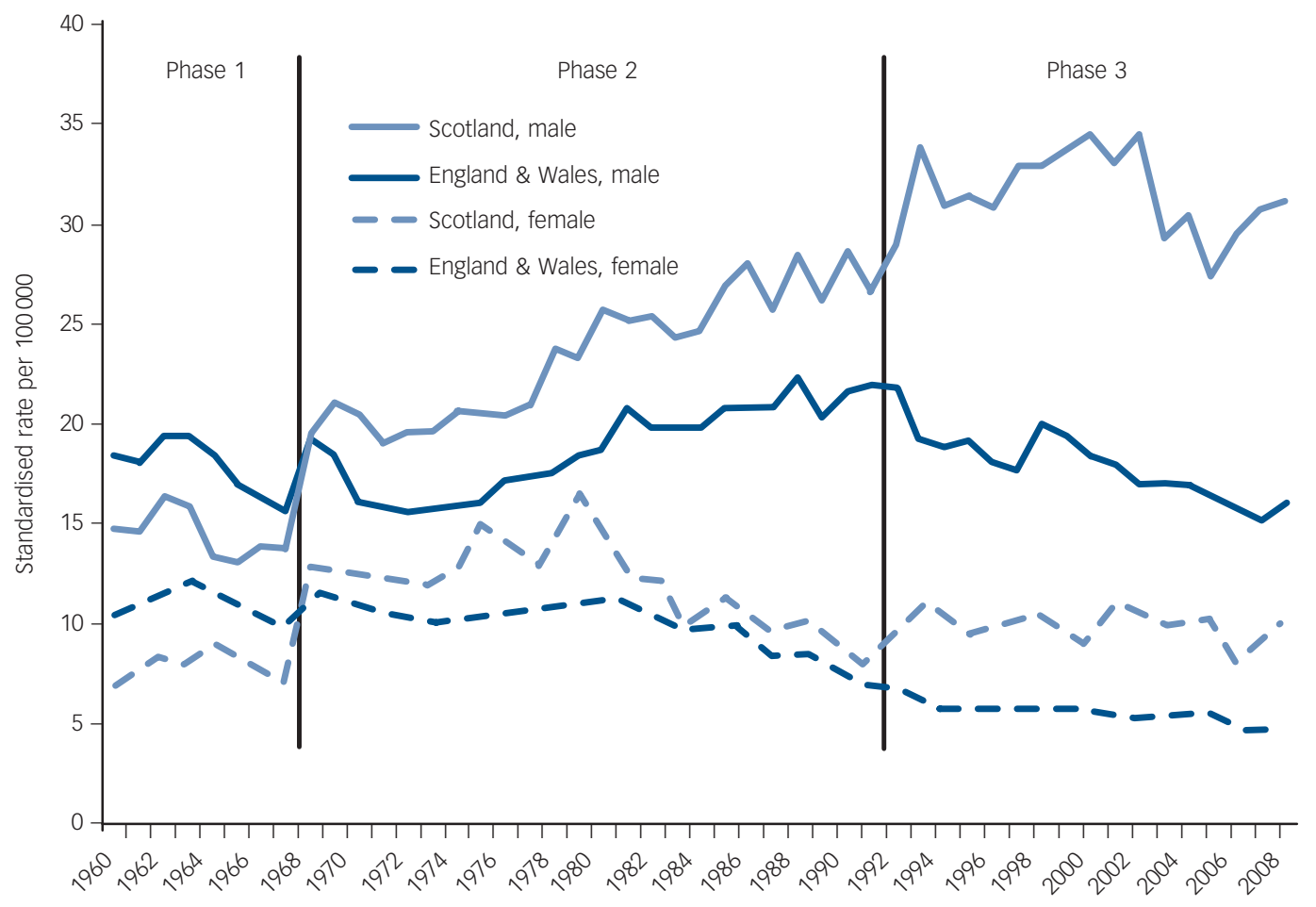

Fig. 1 Age-standardised suicide rates 1960-2008, analysed by country and by gender. Suicide rates include deaths from self-inflicted injury and 'undetermined intent'. 
those aged 15-44 years, suicide rates for those aged 65 years and over declined overall in England \& Wales and Scotland and for both genders across the period 1968-2008, particularly in England \& Wales and for women.

(a)

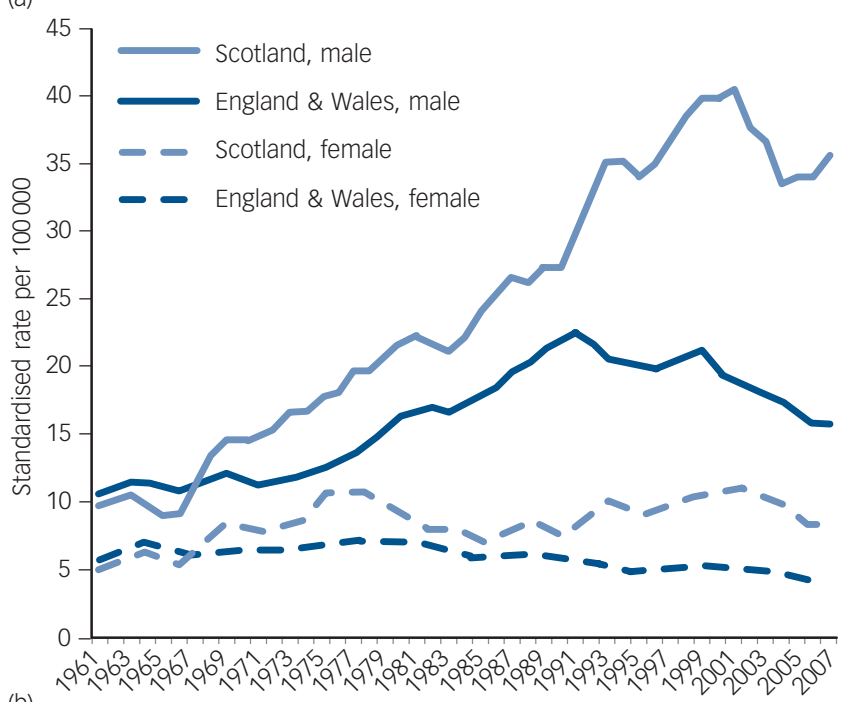

(b)

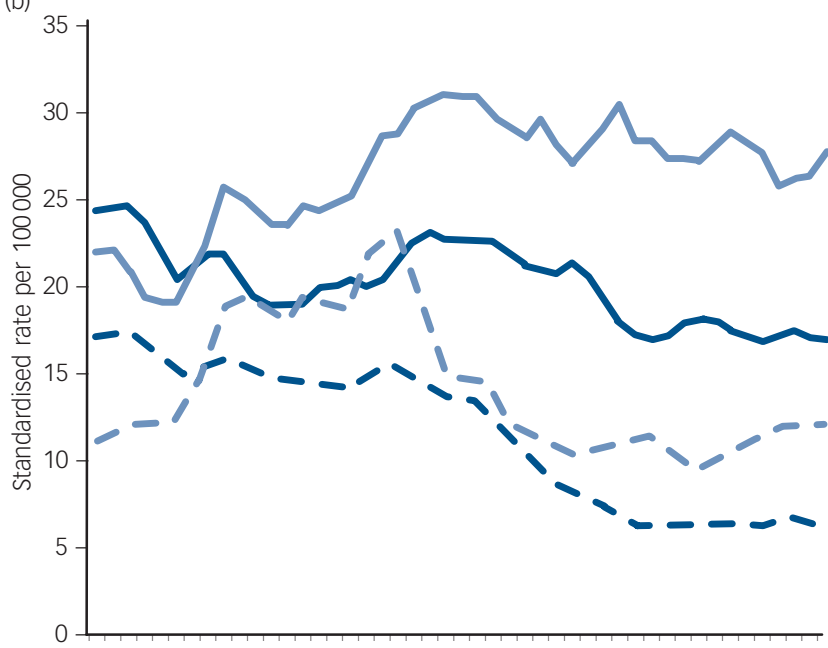

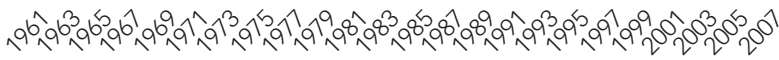

(C)

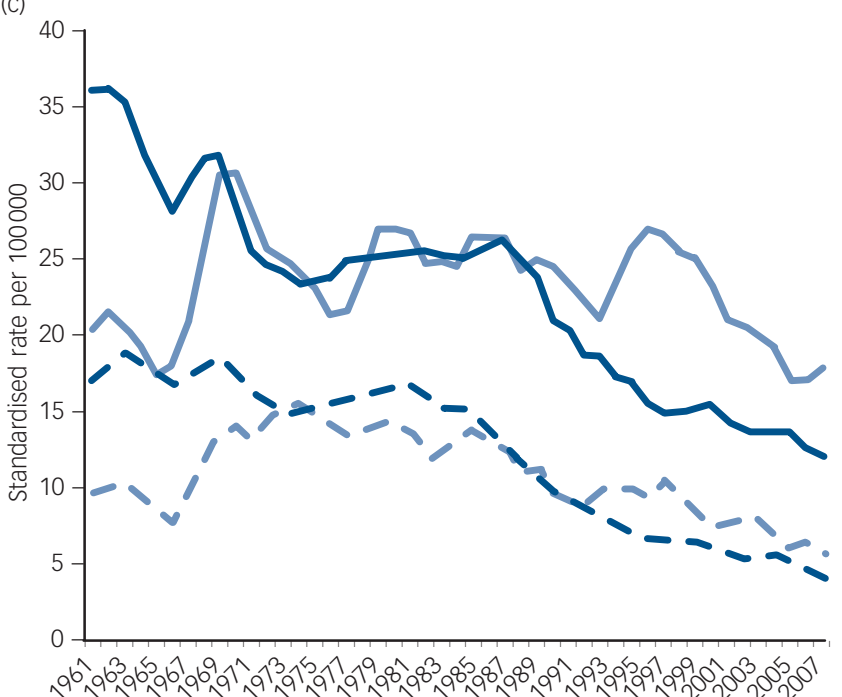

Fig. 2 Age-standardised suicide rates, 1960-2008, expressed as 3-year moving averages: (a) ages 15-44 years; (b) ages 45-64 years; (c) age 65 years and over.
The three phases identified in Fig. 1 can also be seen in Fig. 2, but the patterns within each phase were different for the three age groups. In the early 1960s, although suicide rates for both young men and women were higher in England \& Wales than in Scotland, there were few differences in the gender-specific rates between the countries. This was in contrast to the pattern of suicide in those aged 65 years and over at this time, where rates in England \& Wales were around 70\% higher than in Scotland. However, owing to the subsequent increase in young adult suicides and decline in suicide in elderly people, this pattern was reversed in later years, with a much bigger difference in rates between the countries seen in young adult suicides than in suicides by elderly people.

\section{Method-specific rates}

Figure 3 shows age-standardised suicide rates for the five most common methods of suicide in the UK:

(a) gas poisoning

(b) solid or liquid poisoning

(c) hanging, suffocation and strangulation (for simplicity, we refer to this as 'hanging' from this point onwards)

(d) drowning

(e) jumping or falling from high places.

The inclusion of 'undetermined intent' deaths in 1968 had a marked impact on rates of suicide by solid and liquid poisoning and drowning across Great Britain, especially in Scotland.

At the beginning of the study period, in 1960, gas poisoning was the most common method used in England \& Wales and Scotland by both men and women, and nearly all of these deaths could be attributed to the use of domestic gas. During the 1960s, however, gas poisoning deaths fell sharply across Great Britain and converged. Between the mid-1970s and early 1990s, deaths by gas poisoning among men increased markedly in Scotland and England \& Wales before falling again. These 'other' (non-domestic) gas poisoning deaths were much less common among women, and the patterns of change in gender-specific rates were very similar between the countries over the past three decades. Other suicide methods show bigger differences in trends between the countries. Male cases of hanging rose substantially over the study period, with the rate of growth being particularly marked in Scotland and among the 15-44 year age group (not shown), leading to a divergence in trends between the countries $(P<0.001$ for test of a difference between countries). For women, rates of suicide by hanging also increased overall, albeit more modestly, between 1960 and 2008, with Scotland showing a higher rate of growth than England \& Wales $(P<0.001)$. Deaths by solid and liquid poisoning and by jumping from high places also showed divergent trends between the countries. As with hanging, the increase in solid and liquid poisoning suicides in Scotland between the mid-1980s and 1991-1993 can be attributed mostly to the increase in deaths among those aged 15-44 years.

Although Fig. 1 shows that male suicide rates in England \& Wales were consistently higher than the rates for Scottish women over the study period, this was not always the case when analysed according to suicide method. Figure 3(b) reveals that since 1968 rates of suicides from solid and liquid poisoning among Scottish women have been higher than for men in England \& Wales. Similarly, suicide rates by drowning (Fig. 3(d)) and jumping (Fig. 3(e)) were also higher for Scottish women than for men in England \& Wales during parts of the study period - between the mid-1970s and 1980s in particular for drowning and from the late 1990s for jumping. 


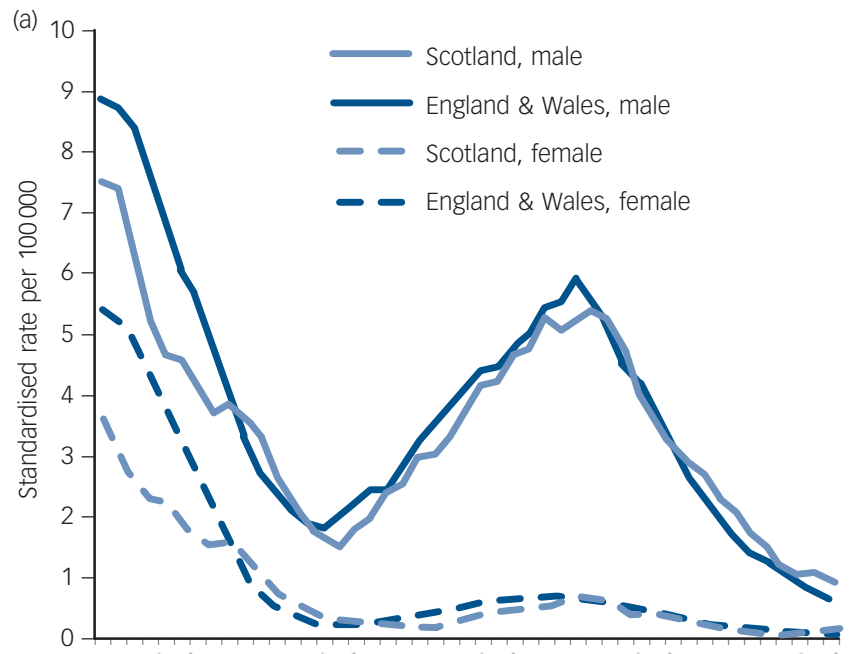

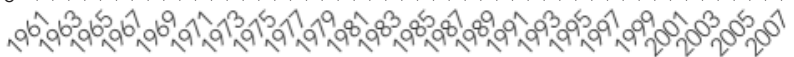

(c)

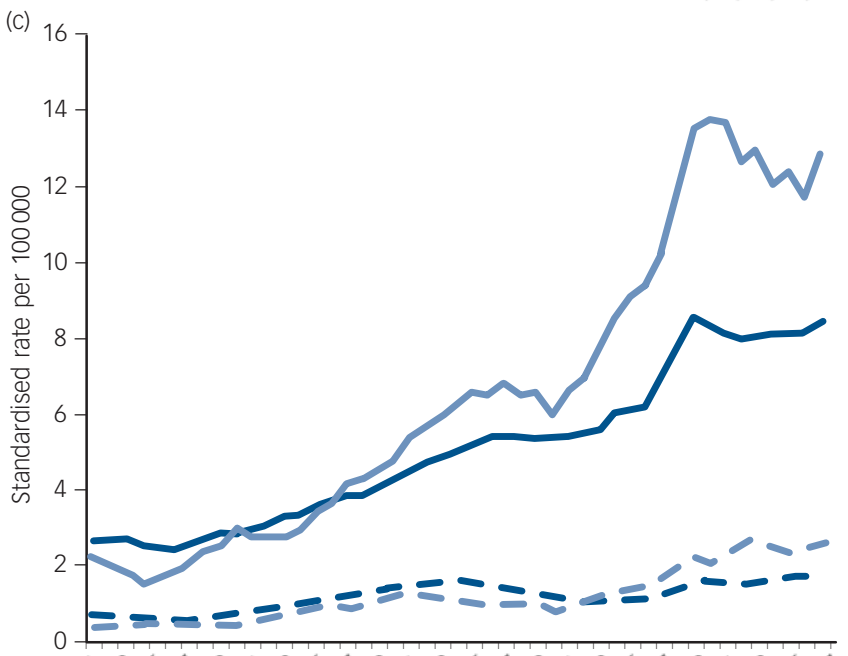

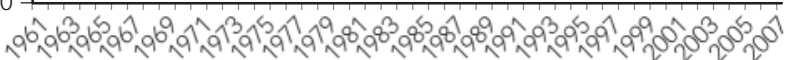

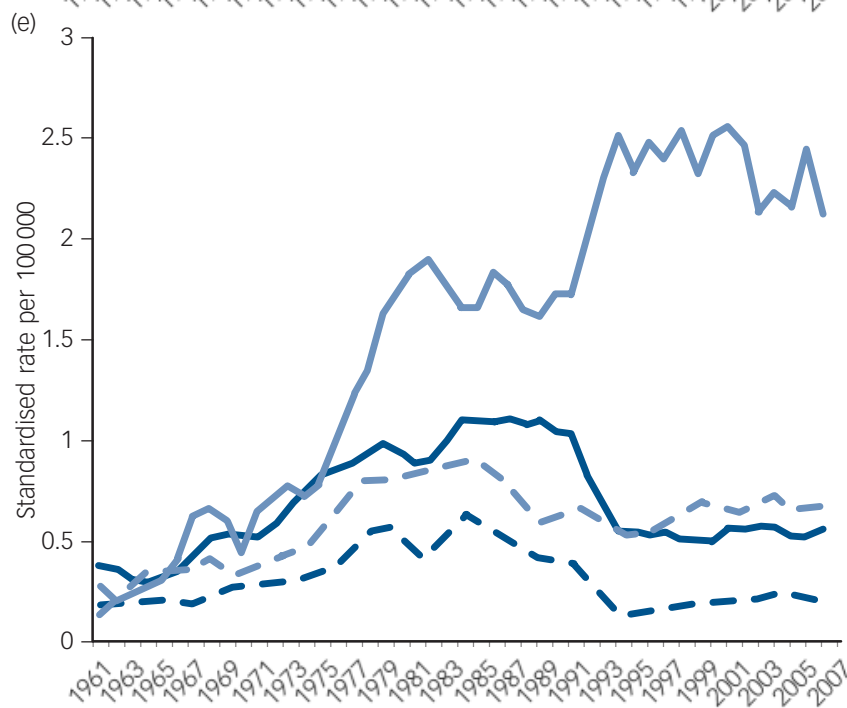

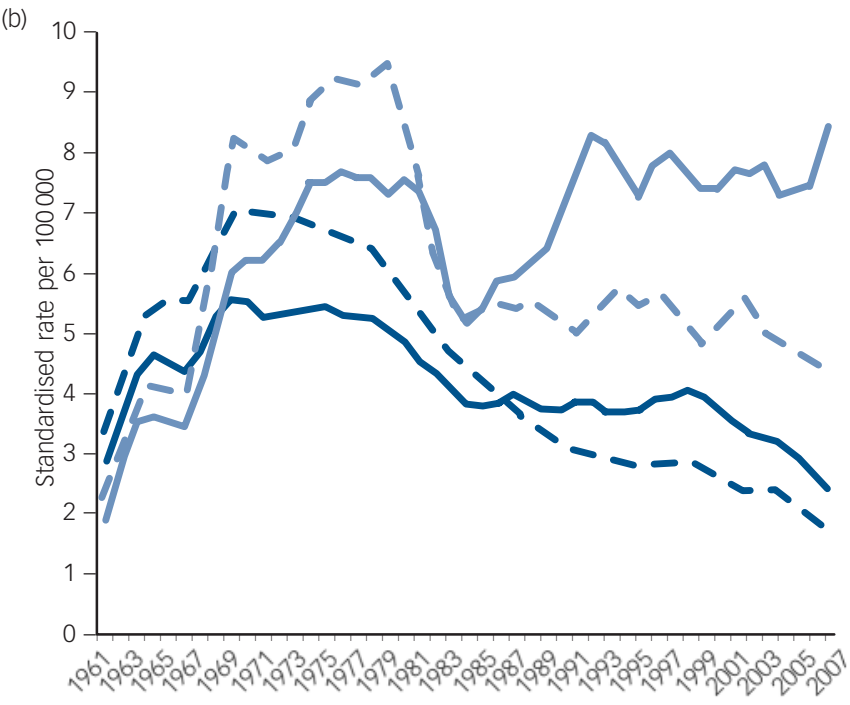

(d)

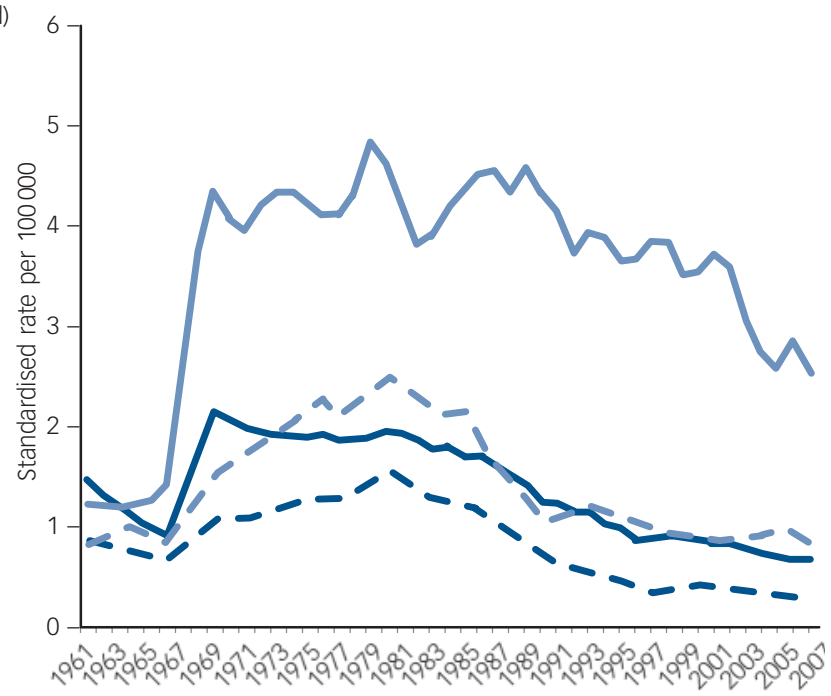

Fig. 3 Age-standardised rates for the more common methods of suicide, 1960-2008: (a) gas poisoning; (b) solid or liquid poisoning; (c) hanging, suffocation or strangling; (d) drowning; (e) jumping or falling from high places. Rates expressed as 3-year moving averages.

We also examined some less common methods of suicide. The use of firearms was relatively rare, but was more common in Scotland than in England \& Wales. The numbers who died by cutting or piercing instruments were even smaller. Owing to the small numbers of these deaths in Scotland each year, statistically significant trends for men and women separately are more difficult to establish than for the other methods reported above. However, there has been a general increase in suicide by cutting in the past decade, with the rate of increase being larger in Scotland than in England \& Wales. Suicide using firearms also 
increased between the early 1970s and mid-1980s, with the rate of increase being over three times higher in Scotland than in England \& Wales. Deaths from firearms, however, subsequently fell in Scotland and England \& Wales and converged by the end of the study period.

\section{Discussion}

At the start of the period under review, the suicide rate in England \& Wales was higher than the rate in Scotland. National suicide rates converged and crossed over at the end of the 1960s, and then diverged markedly over the next four decades. Over the study period, three distinct phases of changing temporal trends could be distinguished: 1960-1967, 1968-1991 and 1992-2008. Much of the divergence in rates since the early 1990s was driven by the marked increase in young adult male suicide and in particular deaths by hanging among this group in Scotland. Unlike the patterns of young adult suicide, suicide rates in elderly people declined overall from the late 1960s across Great Britain and in both genders, particularly in England \& Wales and for women, further contributing to the overall divergence in rates. Introduction of the 'undetermined intent' category of classifying unnatural deaths in 1968 had a significant impact on suicide statistics across Great Britain, especially in Scotland.

\section{Likely explanations and comparison with previous evidence}

The large, sudden increase in suicides in 1968, when deaths of undetermined intent were included, suggests that many possible suicide deaths could have occurred in earlier years but had not been classified as such. The extent of any underreporting before 1968 also appears to be more pronounced in Scotland, and for deaths from solid and liquid poisoning and drowning. These deaths had been reported as being more likely to be designated as 'undetermined intent' compared with those resulting from 'active' methods such as hanging, jumping or firearms. ${ }^{15,16}$ Comparison of the mortality rates from domestic accidents between the countries during 1961-1967 reveals that, although suicide rates were lower in Scotland than in England \& Wales, mortality rates for domestic accidents were around $70 \%$ higher for men and 30\% higher for women in Scotland. ${ }^{10}$ It therefore seems plausible that a significant number of the probable suicides in Scotland were classified as accidents prior to 1968 , and that suicides there had therefore been underestimated. ${ }^{17}$

The marked decline in gas suicides among men and women in England \& Wales and Scotland during the 1960s was associated with the detoxification of domestic gas. ${ }^{18}$ Crombie has previously argued that the convergence of the national suicide rates occurred because of differences in falls in rates for people aged 45 years or over, and not because of differences in frequency and decline of coal gas suicides. ${ }^{5}$ In agreement with this earlier study, our analysis has shown that differences in the rates of change among those aged 45 years and over between the countries had contributed to the convergence. Our results, however, additionally suggest that much of the convergence could be explained by the differences in the rates of change in solid and liquid poisoning and hanging deaths between the countries.

The small divergence in trends between the countries during the second phase was the result of the slightly faster rates of increase in middle-aged (45-64 years) suicides in Scotland than in England \& Wales, and not because of changes in the incidence of young (15-44 years) or elderly (65 years and over) suicides. Analysis by suicide method additionally reveals that the increases in gas poisoning suicides between the mid-1970s and early 1990s did not contribute to the small divergence in suicide trends during this period, as there was no significant difference between the countries in the rates of increase in these deaths. Much of the divergence during the second phase was instead associated with the differences in rates of change between the countries in deaths from solid and liquid poisoning, hanging, and jumping from high places. Unlike in the 1960s, nearly all of these gas poisoning deaths in later years were from motor vehicle exhaust gas as opposed to domestic gas. ${ }^{8,19}$

The marked divergence in national suicide trends during the third temporal phase, between 1992 and 2008, was mostly associated with the increase in young adult male suicides in Scotland and the decline in suicide among all age groups in England \& Wales. Following the introduction of the legislation in 1993 that required all new petrol vehicles to be fitted with catalytic converters, ${ }^{20}$ suicides from motor vehicle exhaust gas poisoning fell. It has previously been reported that the fall of these deaths in England \& Wales resulted in an overall reduction in the male suicide rate in the country, despite the rise in hanging deaths during the same period. ${ }^{20}$ In Scotland, however, the fall in suicide from motor vehicle exhaust gas among men did not lead to a decrease in overall suicide rates in the country. ${ }^{21,22}$ The decline of these gas poisoning deaths was offset by increases in suicide by hanging, contributing to the overall divergence in suicide rates between the countries over time.

The reasons for the marked differences in suicide rates by drowning and jumping between Scotland and England \& Wales are unclear. Proximity to water and high-rise structures alone is unlikely to account for these differences, as the choice of method used is complex and cannot always be explained by ease of access alone. Further investigation is needed to explore the reasons behind these differences.

\section{Strengths and limitations}

We have presented an up-to-date examination of the changing patterns in suicide risk between Scotland and England \& Wales. We have also combined deaths from self-inflicted injury with those of undetermined intent in our analysis, thus presenting more accurate estimates of the total probable suicides. ${ }^{13-15}$ This is unlike most other reported cross-countries comparisons, which only included mortality data from self-inflicted injury, and thus would have underestimated the suicide rates across Great Britain - particularly in Scotland - during the early period. ${ }^{5,6,23,24}$

The mortality data used in this study cover four ICD versions. Double-coding exercises have previously concluded that these changes have had no impact on the overall number of suicides or deaths classified as undetermined intent. ${ }^{25-28}$ A limitation of this study, however, is the use of mortality data based on year of registration of death, as opposed to year of occurrence. Although there is no delay in the initial registration of suicide and suspected suicide in Scotland, the registration of these deaths in England \& Wales is often delayed pending a verdict from the coroner's inquest. ${ }^{1}$ This poses a potential time-lag issue when comparing death rates between the countries in a particular year. We do not, however, believe that this is likely to have influenced our main findings and conclusions.

\section{Implications}

Identifying the changing patterns of suicide trends between Scotland and England \& Wales is an important first step towards a better understanding of the underlying explanations. It has previously been suggested that the variation in suicide rates between the countries in the late 1960s could be a result of their different ascertainment procedures for unnatural deaths, and perhaps also the differences in their working definitions of 
suicide. ${ }^{4,13}$ It is, however, extremely unlikely that they could explain the marked increase in differentials, especially since the early 1990s. Socioeconomic deprivation and unemployment have previously been shown to be associated with increases in suicide risks, ${ }^{29-31}$ and variations in these factors may therefore have contributed to the between-country differences in suicide rates. Hanlon et al, however, found that deprivation has been accounting for less of the excess mortality (from all causes) in Scotland compared with the rest of Great Britain over the past few decades. ${ }^{32}$ The causes of this decreasing influence of socioeconomic deprivation on the mortality differential between Scotland and England \& Wales - the 'Scottish effect' - are unclear, although deindustrialisation and changes in political context, leading to social, cultural and economic disruption, have been suggested as some of the most likely explanations. ${ }^{33}$ In addition, heavy drinking has been shown to increase risks of suicide, irrespective of other psychiatric disorders. ${ }^{34}$ It is, therefore, possible that any between-country variations in the patterns of alcohol consumption may have contributed to the differentials in suicide risks. Further investigation is needed to determine the importance of these social and behavioural factors, and why they seem to have a particularly strong impact on suicide risk among young Scottish men.

We have also shown that suicide rates are dependent on changes in the availability and lethality of different methods. During the study period these changes included the detoxification of domestic gas, ${ }^{18}$ the replacement of barbiturates with the less toxic benzodiazepines, ${ }^{35}$ the compulsory fitting of catalytic converters in new petrol vehicles from $1993,{ }^{20}$ the introduction of the legislation in 1998 on restricting the pack size of paracetamol and salicylates, ${ }^{36}$ and the withdrawal of co-proxamol in $2005 .{ }^{37}$ It is unlikely that these national changes alone can account for the diverging suicide trends, as they were implemented at the same time across Great Britain. One of the key changes in methods used during the study period, however, was the marked increase in suicide by hanging, particularly among young men in Scotland. This is of particular concern as hanging has high case fatality and is difficult to prevent, except within institutional settings. ${ }^{38}$ It has been proposed that population-based initiatives would be the most useful way to tackle the increase of suicide deaths by hanging, to counter the perception of hanging as a 'clean, painless and rapid method that is easily implemented' ${ }^{38,39}$

\footnotetext{
Pearl L. H. Mok, PhD, Navneet Kapur, FRCPsych, Kirsten Windfuhr, PhD, Centre for Suicide Prevention, University of Manchester, Manchester Academic Health Science Centre, Manchester; Alastair H. Leyland, PhD, Medical Research Council/ Science Centre, Manchester; Alastair H. Leyland, PhD, Medical Research Coun
Chief Scientist Office Social and Public Health Sciences Unit, Glasgow; Louis Appleby, FRCPsych, Centre for Suicide Prevention, University of Manchester; Stephen Platt, PhD, Centre for Population Health Sciences, University of Edinburgh Medical School, Edinburgh; Roger T. Webb, PhD, Centre for Suicide Prevention, University of Manchester, Manchester, UK

Correspondence: Dr Roger Webb, Centre for Suicide Prevention, University of Manchester, Room 2.311, Jean McFarlane Building, Oxford Road, Manchester M13 9PL, UK. Email: roger.webb@manchester.ac.uk

First received 4 Mar 2011, final revision 12 Sep 2011, accepted 28 Sep 2011
}

\section{Funding}

We thank the Chief Scientist Office of the Scottish Government for funding this study.

\section{Acknowledgements}

We are grateful to Miss Cathy Rodway (Centre for Suicide Prevention, University of Manchester) for carrying out the pilot study, and Ms Vanessa Fearn (Office for National Statistics) and Ms Karen Hawkes (General Register Office for Scotland) for their advice Statistics) and Ms Karen Hawkes (General Register Office for Scotland) for their advice
and help in compiling the mortality data. We gratefully acknowledge advice given by Dr Frank Popham, School of Geography and Geosciences, University of St Andrews, on the study methodology.

\section{Appendix}

The World Health Organization International Statistical Classification of Diseases and Related Health Problems coding ranges used to define death by suicide are shown in Table A1 and the codes used to define specific suicide methods are shown in Table A2.

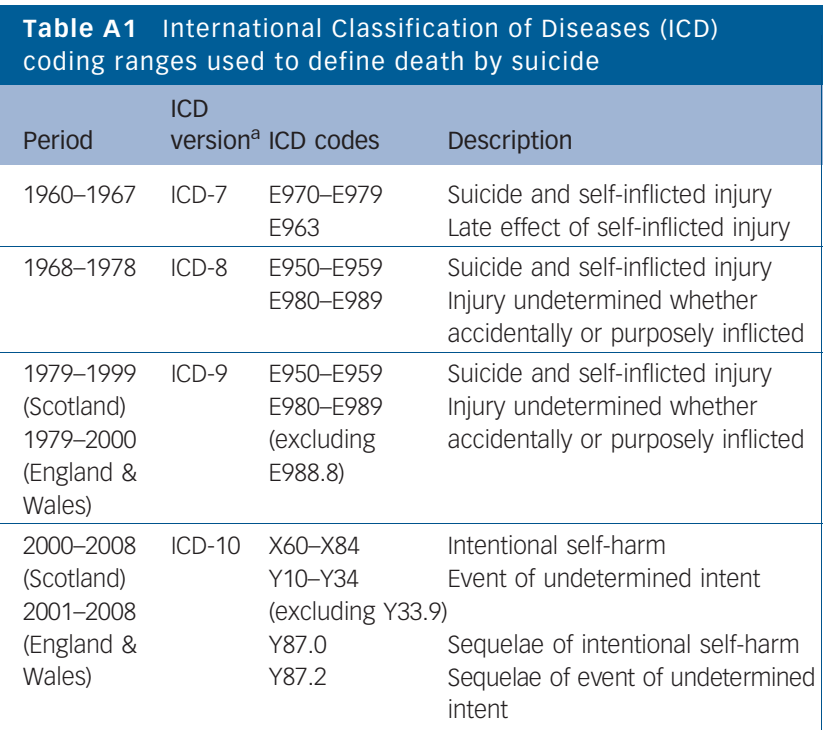

a. World Health Organization. International Statistical Classification of Diseases and Related Health Problems. ICD-7, 1955; ICD-8, 1967; ICD-9, 1978; ICD-10, 1992

Table A2 International Classification of Diseases (ICD) coding ranges used to define specific suicide methods

\begin{tabular}{|c|c|c|}
\hline Method of suicide & $\mathrm{ICD}_{\text {version }}{ }^{\mathrm{a}}$ & ICD codes \\
\hline Solid or liquid poisoning & $\begin{array}{l}\text { ICD-7 } \\
\text { ICD-8 } \\
\text { ICD-9 } \\
\text { ICD-10 }\end{array}$ & $\begin{array}{l}\text { E970, E971 } \\
\text { E950, E980 } \\
\text { E950, E980 } \\
\text { X60-X65, X68-X69 } \\
Y 10-Y 15, Y 18-Y 19\end{array}$ \\
\hline Gas poisoning & $\begin{array}{l}\text { ICD-7 } \\
\text { ICD-8 } \\
\text { ICD-9 } \\
\text { ICD-10 }\end{array}$ & $\begin{array}{l}\text { E972-E973 } \\
\text { E951-E952, E981-E982 } \\
\text { E951-E952, E981-E982 } \\
\text { X66-X67, Y16-Y17 }\end{array}$ \\
\hline $\begin{array}{l}\text { Hanging, suffocation } \\
\text { and strangulation }\end{array}$ & $\begin{array}{l}\text { ICD-7 } \\
\text { ICD-8 } \\
\text { ICD-9 } \\
\text { ICD-10 }\end{array}$ & $\begin{array}{l}\text { E974 } \\
\text { E953, E983 } \\
\text { E953, E983 } \\
X 70, Y 20\end{array}$ \\
\hline Drowning & $\begin{array}{l}\text { ICD-7 } \\
\text { ICD-8 } \\
\text { ICD-9 } \\
\text { ICD-10 }\end{array}$ & $\begin{array}{l}\text { E975 } \\
\text { E954, E984 } \\
\text { E954, E984 } \\
X 71, Y 21\end{array}$ \\
\hline Firearms and explosives & $\begin{array}{l}\text { ICD-7 } \\
\text { ICD-8 } \\
\text { ICD-9 } \\
\text { ICD-10 }\end{array}$ & $\begin{array}{l}\text { E976 } \\
\text { E955, E985 } \\
\text { E955, E985 } \\
\text { X72-X75, Y22-Y25 }\end{array}$ \\
\hline $\begin{array}{l}\text { Cutting and piercing } \\
\text { instruments }\end{array}$ & $\begin{array}{l}\text { ICD-7 } \\
\text { ICD-8 } \\
\text { ICD-9 } \\
\text { ICD-10 }\end{array}$ & $\begin{array}{l}\text { E977 } \\
\text { E956, E986 } \\
\text { E956, E986 } \\
X 78, \text { Y28 }\end{array}$ \\
\hline $\begin{array}{l}\text { Jumping or falling } \\
\text { from high places }\end{array}$ & $\begin{array}{l}\text { ICD-7 } \\
\text { ICD-8 } \\
\text { ICD-9 } \\
\text { ICD-10 } \\
\end{array}$ & $\begin{array}{l}\text { E978 } \\
\text { E957, E987 } \\
\text { E957, E987 } \\
\text { X80, Y30 } \\
\end{array}$ \\
\hline $\begin{array}{l}\text { Other or unspecified } \\
\text { methods }\end{array}$ & $\begin{array}{l}\text { ICD-7 } \\
\text { ICD-8 } \\
\text { ICD-9 } \\
\text { ICD-10 }\end{array}$ & 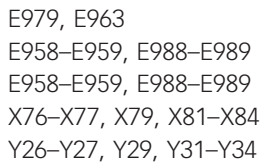 \\
\hline
\end{tabular}




\section{References}

1 Brock A, Baker A, Griffiths C, Jackson G, Fegan G, Marshall D. Suicide trends and geographic variations in the United Kingdom, 1991-2004 (revised version 20-03-2007). Health Stat Q 2006; 31: 6-22.

2 Gunnell D, Middleton N. National suicide rates as an indicator of the effect of suicide on premature mortality. Lancet 2003; 362: 961-2.

3 Sibbald J. Suicide in Scotland. BMJ 1900; 1: 496-8.

4 Kreitman N. Suicide in Scotland in comparison with England and Wales. $\mathrm{Br} J$ Psychiatry 1972; 121: 83-7.

5 Crombie IK. Suicide in England and Wales and in Scotland. An examination of divergent trends. Br J Psychiatry 1990; 157: 529-32.

6 Lester D, Cantor $\mathrm{CH}$, Leenaars AA. Suicide in the United Kingdom and Ireland. Eur Psychiatry 1997; 12: 300-4.

7 McClure GMG. Changes in suicide in England and Wales, 1960-1997. Br J Psychiatry 2000; 176: 64-7.

8 McLoone P, Crombie IK. Trends in suicide in Scotland 1974-84: an increasing problem. BMJ 1987; 295: 629-31.

9 Office for National Statistics. The 20th Century Mortality Files, 1901-2000 (England and Wales). ONS, 2011.

10 General Register Office for Scotland. Registrar General for Scotland Annual Report 1961-1987, 1996-2000. Government Statistical Service, 1962-1988, 1997-2001.

11 General Register Office for Scotland. Vital Events Reference Tables. Genera Register Office for Scotland, 2011 (http://www.gro-scotland.gov.uk/statistics/ theme/vital-events/general/ref-tables/index.html).

12 office for National Statistics. Mortality Statistics: Deaths Registered in 2008. ONS, 2009.

13 Barraclough BM. Are the Scottish and English suicide rates really different? Br J Psychiatry 1972; 120: 267-73.

14 Charlton J, Kelly S, Dunnell K, Evans B, Jenkins R, Wallis R. Trends in suicide deaths in England and Wales. Popul Trends 1992; 69: 10-6.

15 Linsley KR, Schapira K, Kelly TP. Open verdict $v$. suicide - importance to research. Br J Psychiatry 2001; 178: 465-8.

16 Platt S, Backett S, Kreitman N. Social construction or causal ascription distinguishing suicide from undetermined deaths. Soc Psychiatry Psychiatr Epidemiol 1988; 23: 217-21.

17 General Register Office for Scotland. Registrar General for Scotland Annual Report 1961. Government Statistical Service, 1962

18 Kreitman N. The coal gas story: United Kingdom suicide rates, 1960-71. Br J Prev Soc Med 1976; 30: 86-93.

19 Bulusu L, Alderson M. Suicides 1950-82. Popul Trends 1984; 35: 11-7.

20 Kelly S, Bunting J. Trends in suicide in England and Wales, 1982-96. Popul Trends 1998: 92: 29-41.

21 Stark C, Hopkins P, Gibbs D, Rapson T, Belbin A, Hay A. Trends in suicide in Scotland 1981-1999: age, method and geography. BMC Public Health 2004; 4: 49
22 Skilling GD, Sclare PD, Watt SJ, Fielding S. The effect of catalytic converter legislation on suicide rates in Grampian and Scotland 1980-2003. Scott Med J 2008; 53: 3-6.

23 Cantor $\mathrm{CH}$, Leenaars $\mathrm{AA}$, Lester $\mathrm{D}$, Slater PJ, Wolanowski AM, O'Toole B. Suicide trends in eight predominantly English-speaking countries 1960-1989. Soc Psychiatry Psychiatr Epidemiol 1996; 31: 364-73.

24 Varnik A, Kolves K, Allik J, Arensman E, Aromaa E, van Audenhove C, et al. Gender issues in suicide rates, trends and methods among youths aged 15-24 in 15 European countries. J Affect Disord 2009; 113: 216-26.

25 General Register Office for Scotland. Registrar General for Scotland Annual Report 1968. Government Statistical Service, 1969.

26 General Register Office for Scotland. Registrar General for Scotland Annual Report 1979. Government Statistical Service, 1980.

27 General Register Office for Scotland. Appendix 2 - The introduction of ICD10 for cause of death coding in Scotland. Registrar General for Scotland Annual Report 2000. National Statistics, 2001.

28 Anonymous. Results of the ICD-10 bridge coding study, England and Wales, 1999. Health Stat $Q 2002 ; 14: 75-83$

29 Crombie IK. Trends in suicide and unemployment in Scotland, 1976-86. BMJ 1989; 298: 782-4

30 McLoone P. Suicide and deprivation in Scotland. BMJ 1996; 312: 543-4.

31 Biddle L, Brock A, Brookes ST, Gunnell D. Suicide rates in young men in England and Wales in the 21st century: time trend study. BMJ 2008; 336 : 539-42.

32 Hanlon $\mathrm{P}$, Lawder RS, Buchanan D, Redpath A, Walsh D, Wood R, et al. Why is mortality higher in Scotland than in England and Wales? Decreasing influence of socioeconomic deprivation between 1981 and 2001 supports the existence of a 'Scottish Effect'. J Public Health 2005; 27: 199-204.

33 McCartney G, Collins C, Walsh D, Batty D. Accounting for Scotland's Excess Mortality: Towards a Synthesis. Glasgow Centre for Population Health, 2011.

34 Flensborg-Madsen $T$, Knop J, Mortensen EL, Becker U, Sher L, Grønbæk M. Alcohol use disorders increase the risk of completed suicide - irrespective of other psychiatric disorders. A longitudinal cohort study. Psychiatry Res 2009; 167: $123-30$

35 Johns MW. Self-poisoning with barbiturates in England and Wales during 1959-74. BMJ 1977; 1: 1128-30.

36 Hawton K, Simkin S, Deeks J, Cooper J, Johnston A, Waters K, et al. UK legislation on analgesic packs: before and after study of long term effect on poisonings. BMJ 2004; 329: 1076-9.

37 Hawton $\mathrm{K}$, Bergen $\mathrm{H}$, Simkin S, Brock A, Griffiths $\mathrm{C}$, Romeri $\mathrm{E}$, et al. Effect of withdrawal of co-proxamol on prescribing and deaths from drug poisoning in England and Wales: time series analysis. BMJ 2009; 338: b2270. doi:10.1136/ bmj.b2270.

38 Gunnell D, Bennewith O, Hawton K, Simkin S, Kapur N. The epidemiology and prevention of suicide by hanging: a systematic review. Int J Epidemiol 2005; 34: $433-42$.

39 Biddle L, Donovan J, Owen-Smith A, Potokar J, Longson D, Hawton K, et al. Factors influencing the decision to use hanging as a method of suicide: qualitative study. Br J Psychiatry 2010; 197: 320-5. 